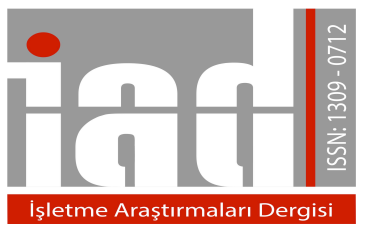

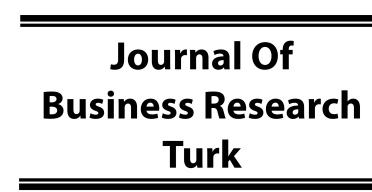

www.isarder.org

\title{
Basel Sermaye Yeterliği Oranındaki Değişimin Türk Bankacılık Sektörü Üzerindeki Etkilerinin İncelenmesi: Katılım Bankaları ve Geleneksel Bankaların Karşılaştırmalı Oran Analizi ${ }^{1}$
}

\author{
Investigation of the Effects of Basel Capital Adequacy Ratio Change \\ on the Turkish Banking Sector: Comparative Conventional and Islamic \\ Banking with Ratio Analysis
}

\author{
Özgür ÇATIKKAŞ \\ Marmara Üniversitesi \\ Bankacılık ve Sigortacılık Yüksekokulu \\ Sigortac1lık Bölümü \\ İstanbul, Türkiye \\ orcid.org/0000-0002-7774-5882 \\ ozgurcatikkas@marmara.edu.tr
}

\author{
Ayhan YATBAZ \\ Manisa Celal Bayar Üniversitesi \\ Uygulamalı Bilimler Yüksekokulu \\ Bankacılık ve Finans Bölümü \\ Manisa, Türkiye \\ orcid.org/0000-0002-6059-4176 \\ ayhanyatbaz@hotmail.com
}

\author{
Selim DURAMAZ \\ Manisa Celal Bayar Üniversitesi \\ Uygulamalı Bilimler Yüksekokulu \\ Bankacılık ve Finans Bölümü \\ Manisa, Türkiye \\ orcid.org/0000-0002-1257-0620 \\ selimduramaz@hotmail.com
}

\section{Özet}

Çalı̧̧mada, sermaye yeterliliğgi oranının, katılım bankaları ve geleneksel bankaların karlılıkları, faiz-kar payı gelirleri gibi kalemleri üzerindeki etkisini ortaya koymak amacıyla Türk bankacılık sektörüne ait veriler oran analizi yöntemiyle incelenmiştir. Buna göre incelenen dönemde her iki banka grubunda da sermaye yeterliliği oranı düşüş eğilimindedir. Her iki grupta da sermaye yeterliliğinin düşmesine neden etkenlerden biri olan kredi ve alacaklar kalemi yıllar içinde artış göstermiş, yine bununla aynı doğrultuda faiz (kar payı) gelirlerinde de bir artış yaşanmıştır. Ancak bu noktada katılım bankaları daha iyi performans göstermiş, katılım bankalarında sermaye yeterliliği oranı daha az düşmesine rağmen faiz (kar payı) gelirlerindeki artış geleneksel bankalara göre daha yüksek olarak gerçekleşmiştir. Buna rağmen sermaye yeterliliği oranının azalması karşısında kredi rakamları artarken, bankaların özkaynak karlılıkları artmamış, bu noktada sermaye yeterliliği oranının azalmasının karlılık rakamları üzerinde herhangi bir kaldıraç etkisi gözlenmemiştir.

Anahtar Kelimeler: Basel Kriterleri, Türk Bankacılık Sektörü, Oran Analizi.

\footnotetext{
${ }^{1}$ Bu çalışma 02-05 Kasım 2017 tarihlerinde Antalya'da düzenlenen Uluslararası Türk Dünyası Stratejik Araştırmalar Kongresi'nde sunulan özet bildirinin genişletilmiş halidir.
} 


\begin{abstract}
In the study, in order to determine the effect of the capital adequacy ratio on the items such as the profitability and interest-share incomes of the Islamic banks and the traditional banks, the datas of Turkish banking sector are examined with ratio analysis method. Accordingly, the capital adequacy ratio of both bank groups tends to decrease in the period examined. In both groups, credit and assets, which are one of the factors causing the decrease in capital adequacy, increased during the period and there was an increase in interest (profit share) revenues in the same way. However, at this point, Islamic banks performed better and the increase in interest (profit share) incomes was higher than that of the more traditional banks, even though the capital adequacy ratio in Islamic banks decreased less. Nevertheless, while the credit figures increased in the face of the decrease in the capital adequacy ratio, the return on equity of the banks did not increase and there was no leverage effect on the profitability figures of the decrease in the capital adequacy ratio at this point.
\end{abstract}

Keywords: Basel Criterias, Turkish Banking Sector, Ratio Analysis.

\title{
Giriş
}

Belli bir zaman aralığında belirli bir hedefe ulaşma çabası aşamasında ortaya çıkan potansiyel sorunların, tehlikelerin ve parasal kayıpların ortaya çıkması ile ekonomik faydanın azalması olarak ifade edilebilen risk kavramı tüm ekonomik sistem içerisinde olduğu gibi bankacılık sektöründe de büyük önem taşımaktadır. Kuruluşlarından bu yana sürekli farklı riskler altında faaliyetlerine devam eden bankalar, günümüz küresel dünyasında ekonomik olarak ayakta kalabilmek ve karlılıklarını sürdürebilmek noktasında faiz, kur, piyasa riskleri gibi birçok riskin etkisi altındadirlar.

Bankalar gerek yerel gerekse küresel düzeyde, mevcut ya da ortaya çıkabilecek farklı riskleri kontrol altına alıp, minimize etmek amacıyla farklı önlemler almakta, farklı oluşumlar içerisine girmektedirler. Bu noktada Uluslararası Ödemeler Bankası (Bank for International Settlements - BIS) tarafından Basel Komitesi, "Basel Kriterleri" olarak adlandırılan birtakım kriterler ile yaklaşık 30 yıldır bankacılık sektöründe ortak standartlar belirlenmesi, uygulanması ve test edilmesi için çalışmalarına devam etmektedir.

Mevcut bankacılık sisteminde bir arada faaliyet gösteren ve işleyişleri açısından birtakım farklılıkları söz konusu olan konvansiyonel ve katılım bankaları açısından bakıldığında, her ne kadar bazı risk kriterleri her iki bankacılık yapısı için geçerli olsa da Basel Kriterleri gibi bazı kriterlerin bu bankalarda uygulanması farklı sonuçlara neden olabilmektedir. Nitekim faiz, kredi ve piyasa riskleri karşısında sektördeki bazı düzenlemeler, bu iki bankacılık yapısının karlılıklarını farklı açılardan etkileyebilmektedir.

$\mathrm{Bu}$ kapsamda çalışmanın amacı Basel Kriterleri çerçevesinde uygulanmakta olan sermaye yeterliliği oranının katılım ve konvansiyonel bankaların karlılıkları üzerindeki etkisinin incelenmesi ve her iki banka grubunun sermaye yeterliliği oranlarının ve karlılıklarının bu kapsamda karşılıklı olarak bir değerlendirmesini yapmaktır. Buna göre çalışmada öncelikle Basel kriterlerinin ilk olarak ortaya çıkışından günümüze kadar olan süreçte gelişimi sunulmuş, daha sonraki bölümlerde ise sermaye yeterliliği oranındaki 
değişimin karlılık, kredi ve faiz gelirleri ile arasındaki ilişkiler değerlendirilmeye çalışılmıştır.

\section{Basel Komitesi, Kuruluşu ve Basel I Kriterleri}

Günümüzde Basel kriterleri olarak bilinen ve bankacılık sektörünü dünya genelinde doğrudan etkileyen düzenlemeleri gerçekleştiren Basel Komitesi'nin oluşumu ve çalışmaları yıllar öncesine uzanmaktadır. Basel Komitesi, İsviçre'nin Basel kentinde Avrupa Merkez Bankalarının bankası olarak faaliyette bulunmak ve aynı zamanda uluslararası ödemeler sistemini düzenlemek amacıyla kurulan Uluslararası Ödemeler Bankası (Bank for International Settlements - BIS) bünyesinde 1974 y1lı sonunda "Bankacılık Düzenleme ve Denetim Uygulaması Komitesi" (Basel Committee on Banking Supervision - BCBS) adıyla faaliyetlerine başlamıştır. Atiker (2005) s.1 ve Goodhart (2011) s i.

Basel Komitesi'nin hayata geçirilmesindeki en önemli amaç, bankacıllk sisteminin etkin bir şekilde işlemesine yönelik bir denetim sisteminin kurulması ve bu noktada tüm bankalarca bazı standartların sağlanmasıdır. Nitekim bankaların risk yönetimlerinin etkin bir şekilde işlemesi, o ülkedeki finansal sistemin istikrarlı olması arasında doğru yönde bir ilişki söz konusudur. Kredi riski, piyasa riski, likidite riski ve diğer risklerin iyi yönetilememesi durumunda bankalarda ortaya çıkabilecek olumsuzlukların farklı sektörlere de ulaşma olasılı̆̆ gösterilmesini zorunlu hale getirmektedir. Gerek finans sektöründe gerekse tüm ekonomide sürdürülebilir bir istikrarının varlığı için, bankaların kendi risk algılamaları ve risk yönetimi isteklerine ilaveten, minimum düzeyde uyumlu olmak zorunda oldukları düzenlemelerin getirilmesi uluslararası finans çevrelerinde temel bir ilke olarak benimsenmiştir. Yayla ve Kaya (2005) s.2.

Nitekim bu çerçeveden hareketler, 1970 ve 1974 yıllarında yaşanan küresel boyuttaki ekonomik krizler ve birçok ülkede bu krizlerin bankacılık sektörüne yansımaları karşısında, sermaye piyasasının en etkin ve en önemli temsilcilerinden bankaların bilanço yapısını daha güçlü hale getirebilmek maksadıyla, 1988 yılında Basel Bankacılık Denetim Komitesi tarafından Basel I uzlaşısı yayınlanarak hayata geçirilmiştir. Böylelikle dünya bankacılık sistemine Basel kriterlerinin ilk adımı atılmıştır. Basel I kriterleri, herhangi bir bankanın iflas etmesi durumunda mudilerin maruz kalabileceği maliyetleri minimuma azaltmak noktasında asgari olarak kayıt altına alınması gerekli sermaye miktarı üzerine odaklanmıştır. Atiker, (2005) s.2.

$$
\text { SYR }=\frac{\text { Özkaynaklar }}{\text { Kredi Riskine + Piyasa Riskine Maruz Varlıklar }} \geq \% 8
$$

Buna göre Basel I'de bankaların sahip olması gereken sermaye yeterliliği ile ilgili standartlar belirlenerek, banka sermayesinin kapsamlı bir şekilde tanımı yapılmıştır. Buna göre de bankanın sermayesinin risk ağırlıklı aktiflere oranının en az \% 8 olması standartı istenilmiştir. Süreç içinde 1996 yılında, Basel I'e ilave edilen bir düzenleme ile, bankaların, kredi riskine ek olarak, üstlendikleri piyasa riski için de sermaye ayırmaları standartlar arasındaki yerini almış ve aşağıdaki şekilde formüle edilmiştir. Karabiyık ve Anbar (2006) s.2-3. 


\section{Basel II Kriterleri}

Bankacılık sistemindeki risk kavramının ve unsurlarının gün geçtikçe önemini daha da artırıyor olması; Basel Komiteleri'nce sunulan değerlendirmelerin BIS tarafından dikkate alınması gerekliliğini zorunlu kılmaktadır. Bu çerçevede yaşanan farklı yapıdaki finansal krizler Basel Komitesi'nin aldıkları kararların zaman zaman yenilenmesine neden olmuş ve dolayısıyla Basel Komitesince sunulan tavsiye kararları da sürekli olarak yenilenmiş ve güncellenmiştir. Mermod ve Ceran (2011) s.35.

Bu kapsamda Basel Komitesi, Haziran 1999'da, finansal piyasalarda meydana gelen gelişmeleri, Basel I'in sermaye yeterliliği ölçümüne ilişkin eksiklikleri ve diğer eksikliklerini dikkate alarak "Basel II-Yeni Basel Sermaye Yeterliliği Uzlaşısı"na ilişkin üç adet istişari metin (Consultative Paper-1-2-3) yayımlanırken, metinler, ülke denetim otoriteleri ve bankalarla birlikte ilgili diğer taraflardan alınan yorum ve öneriler kapsamında revize edilmiş ve Basel II kapsamındaki nihai metin Haziran 2004'te yayımlanmıştır. BDDK (2005) s.2.

Minimum sermaye yeterliliği, sermaye yeterliliğinin denetimi ve piyasa disiplini olmak üzere üç yapısal blok üzerinde ilerlemesi öngörülen Basel II genel olarak bankacılık sisteminde etkin risk yönetimini ve piyasa disiplinini geliştirmek, sermaye yeterliliği ölçümlerinin etkinliğini artırmak, sağlam ve aynı zamanda etkin bir bankacılık sistemi meydana getirmek ve finansal istikrara katkıda bulunmak amaçlarına odaklanmıştır. Aynı zamanda Basel II uzlaşısı, sermaye yükümlülüğünün nasıl hesaplanacağı, karşılaşılan farklı yapıdaki risklerin ne şekilde yönetileceği, sermaye yeterliliğinin nasıl değerlendirileceği ve sonuçların kamuoyuna nasıl açıklanacağına yönelik hükümleri de içermektedir. Elizalde, (2007) s.i ve BDDK (2005) s.1.

$$
\text { SYR }=\frac{\text { Özkaynaklar }}{\text { Kredi Riskine + Piyasa Riskine + Operasyonel Riske Maruz Varlıklar }} \geq \% 8
$$

Basel I'de sadece kredi ve piyasa riskleri için \%8 olarak belirlenen asgari sermaye yeterliliği hesaplanmasına farklı olarak operasyonel risk de ilave edilmiştir. Buna göre

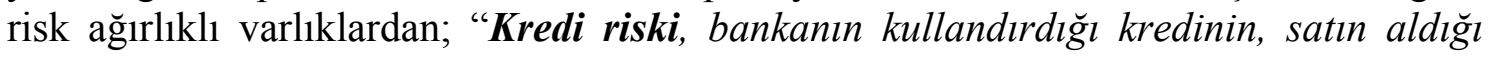
menkul kıymetin veya herhangi bir şekilde verdiği paranın geri dönüşünün kısmen ya da tamamen olmamasını, piyasa riski, finansal piyasalarda oluşan volatiliteye (oynaklı̆ga) bağll olarak, faiz oranlarl, döviz kurlarl ve hisse senedi fiyatlarında meydana gelen değişimler sonucunda, bir bankanın zarar etme veya sermaye kaybetme riskini, operasyonel risk ise, bir bankanın işlemeyen ya da uygun olmayan iç süreçler, insanlar, sistemler ya da dış etkenler nedeniyle ortaya çıkabilecek zarara uğrama riskini" ifade etmektedir. Basel II düzenlenmesine göre "Asgari Sermaye Yeterliliği Oranı" aşağıdaki şekilde hesaplanmaktadır. Basel II ve KOBİ’ler Çalışma Grubu (2006) s.6:

\section{Basel III Kriterleri}

Eylül 2008'de Lehman Brothers'ın iflasını ilân etmesi ile ortaya çıkan yeni bir kriz süreci kapsamında, ABD'deki büyük yatırım bankalarının banka holding şirketlerine dönüştürülmesi, Fannie Mae ve Fredi Mac kuruluşlarının kamusallaştırılması, AIG bankın iflasın eşiğine gelmesi, Fortis Bank'ın bölünmesi ve daha sonra satılması, İzlanda'da öncelikle en büyük ticari bankanın, daha sonra ise ülkenin bankacılık sisteminin tamamıyla çökmesi, birçok devletin ülkesindeki bankalara ciddi destekleme paketleri sunulması gibi gelişmeler, geçmişten günümüze dek olan 
süreçte olası kriz süreçleri için yeteri kadar önlemin alınmadığını ve mevcut sistemin bazı ciddi eksiklikler içerdiğini ortaya çıkarmıştır. BDDK (2010) s.4.

Krizin baş aktörü olan bankacılık sektöründe ortaya çıkan kriz, süreç içinde tüm küresel finansal sektörünü ve ülke ekonomilerini krize dahil ederek kısa sürede tüm dünyaya yayılmıştır. BIS (2010) s.2. Yaşanan bu gelişmeler üzerine Basel Bankacılık Denetim Komitesi 12 Eylül 2010 tarihli toplantısında, yeni bir sermaye düzenlemesi paketini kamuoyuna sunmuştur. Basel I ve Basel II'den sonra komite tarafindan kamuoyuna sunulan üçüncü reform paketi olması nedeniyle, bu çalışma dünya genelinde Basel III Uzlaşısı veya kısaca Basel III adını almışır. Boyner (2011) s.1.

Basel III, bankacılık sektörünün düzenleme, gözetim ve risk yönetimi güçlendirmek için Bankacılık Denetleme Basel Komitesi tarafından geliştirilen kapsamlı bir dizi reform önlemleri öngörmektedir. Bu önlemler öncelikli olarak şunları hedefler. BIS (2012):

- Kaynağı ne olursa olsun mali ve ekonomik şokları engelleyebilmek için bankacılık sektörünün gelişim kabiliyetini temin etmek

- Risk yönetimi ve yürütülmesini geliştirmek

- Bankaların şeffaflığını güçlendirmek

Basel III, bankaların özkaynakları, sermayeye ilişkin oranları ile kaldıraç ve likidite oranlarında bazı düzenlemeler öngörmektedir. Ancak Basel III'ün yukarıda öngörülen hedeflerin yanında ulaşmaya çalıştığı asıl hedef, ABD ve Avrupa bankalarının hem sermaye kalitelerinin arttırılması hem de kriz dönemleri için yeterli sermayeye sahip olmalarıdır. Bu noktada sermayenin yeniden tanımı yapılmış, likidite riski için miktar tespiti yapılmış, tüm sermaye bileşenleri için, bankanın bulundurması gereken minimum sermaye oranları ayrı ayrı belirlenmiştir. Buna göre bankaların sermaye bileşenleri sermaye oranlarının asgari $\% 4,5$, ana sermaye oranlarının ise $\% 6$ olması gerektiği ifade edilmiştir. Toplam sermaye oranı da $\% 8$ olarak bırakılmış yani Basel II'ye göre bir değişiklik yapılmamıştır. $\mathrm{Bu}$ oranlarla birlikte bankaların çıkabilecek olası bir krize karşılık \%2,5 oranında ek sermaye ayırmaları gerekmektedir. Böylece sermaye yedeği ile birlikte toplam sermaye yeterlilik oranı 10,5 olmaktadır. Yardımcıoğlu ve Demirel (2010) s.77; Penikas (2015) s.16.

Tablo 1: Basel II Uzlaşısı ve Basel III Kriterlerinde Asgari Oranlar

\begin{tabular}{|c|c|c|c|c|}
\hline \multirow{3}{*}{ ORANLAR } & & \multirow{2}{*}{\multicolumn{3}{|c|}{$\frac{\text { Basel II }}{\text { Asgari OranAsgari OrarKoruyucu Tampor }}$}} \\
\hline & & & & \\
\hline & & $\%$ & $\%$ & Dahil \% \\
\hline Sermaye Yeterlilik Rasyosu & $\frac{\text { Özkaynaklar }}{\text { Risk Ağırlıklı Aktifler }}$ & 8 & 8 & 10.5 \\
\hline Minumum Ana Sermaye Rasyos & $\frac{\text { Ana Sermaye }}{\text { Risk Ağırlıklı Aktifler }}$ & 4 & 6 & 8.5 \\
\hline Çekirdek Ana Sermaye Rasyosu & $\begin{array}{l}\text { Cekirdek Ana Sermaye } \\
\text { Risk Ağırlıklı Aktifler }\end{array}$ & 2 & 4.5 & 7 \\
\hline
\end{tabular}

Kaynak: Koğar, 2010 ve Şahin, 2013:154. 


\section{Sermaye Yeterliliği Oranındaki Değişim ile Bazı Finansal Oranlar Arasındaki İlişkinin İncelenmesi: Katılım Bankacılığı ve Geleneksel Bankacılık Karşılaştırmalı Oran Analizi}

AB ülkeleri dışındaki ülkelerde uygulanması zorunlu olmamasına rağmen Türk Bankacılık sektörü, BDDK rehberliğinde Basel kriterlerinin ortaya çıkmasından günümüze farklı yönetmeliklerle söz konusu kriterlere uyum aşamasında önemli bir mesafe kat etmiştir. Hatta Basel II düzenlemeleri kanunlaştırılarak, 28/06/2012 tarih ve 28337 sayılı Resmî Gazete'de yayımlanarak 01/07/2012 tarihinde yürürlüğe girmiştir.

Çalışmada bankalar analize tabi tutulurken bankacılık sistemi grup bazında üç kategoriye ayrılmıştır. Bunlar; mevduat bankaları, katılım bankaları ve yatırım ve kalkınma bankalarıdır. Banka gruplarının tüm bankacılık sektörü içindeki yerini daha iyi görebilmek için ayrıca sektör bilgilerine de yer verilmiştir. Çalışmada geleneksel bankalar ifadesi mevduat bankaları ile yatırım ve kalkınma bankalarını ifade etmek için kullanılmıştır.

\subsection{Bankacılık Sektörü Genel Görünümü}

Öncelikle katılım bankalarının geleneksel bankalar karşısındaki genel durumun görülmesi noktasında çalışmada bilanço grubu bazında banka gruplarının dağılımı verilmiştir. Buna göre Grafik 1'de buna yönelik olarak 2015 y1lı sonu verilerinden yararlanılarak bilanço kalemlerinin oransal dağılımı sunulmuştur.

\section{Grafik 1: Banka Grupları Bazında 2015 Yılına İlişkin Bazı Bilanço Kalemlerinin Oransal Dağılımı}

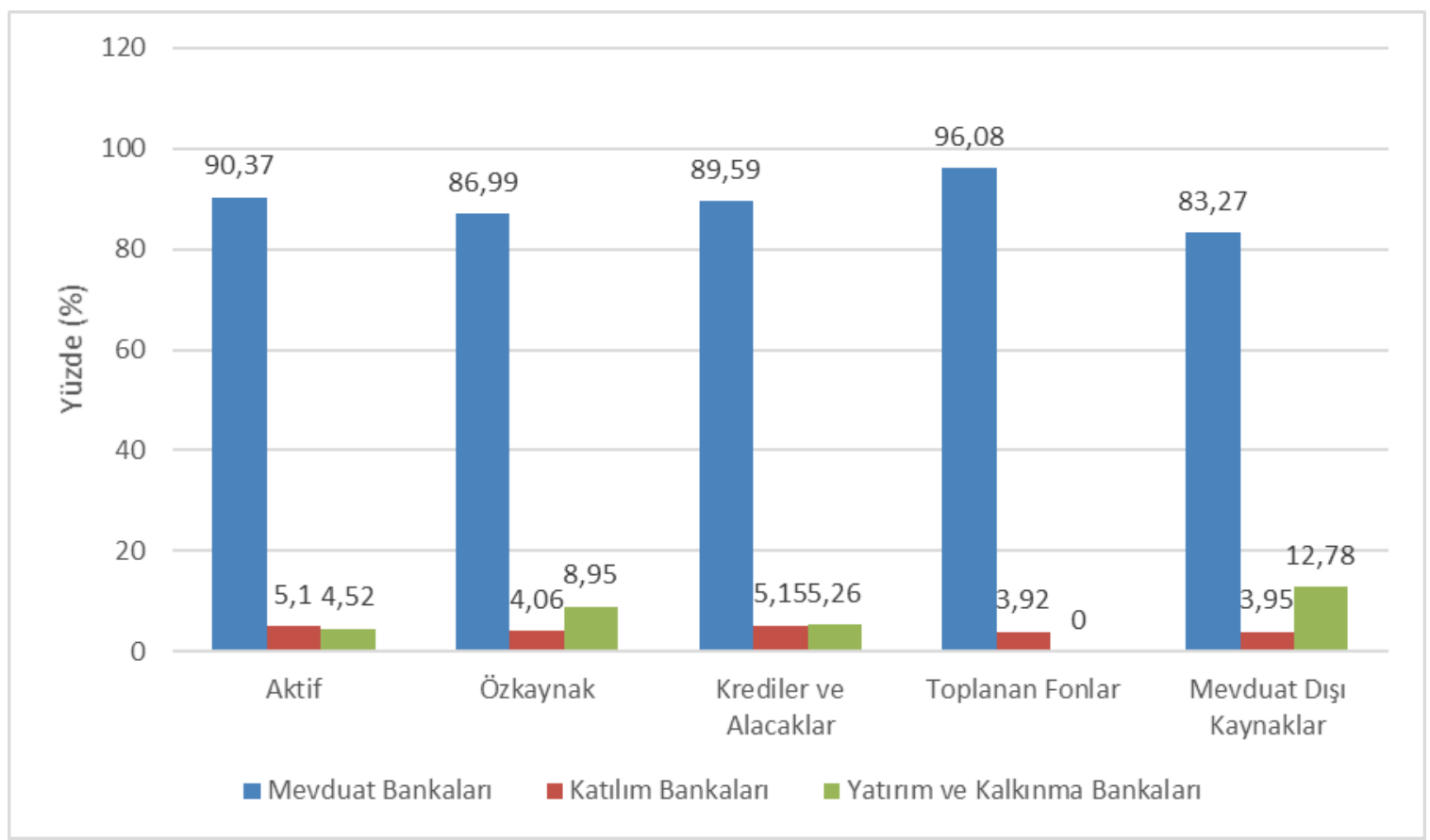

Kaynak: BDDK, TBB, TKBB, 2016.

Grafik 1'e bakıldığında, 2015 yılı verilerine göre bankacılık sektörünün aktifleri arasındaki en yüksek pay mevduat bankalarına aittir. Mevduat bankaları toplam aktiflerin \%90,37'sine sahipken, bu oran katılım bankalarında \%5,1, yatırım ve kalkınma bankalarında ise \%4,5 düzeyindedir. Benzer durum özkaynaklar için de geçerlidir. Buna göre mevduat bankaları toplam özkaynakların \%86,99'una, katılım 
bankaları \%4,06'sına, yatırım ve kalkınma bankaları ise \%8,95'ine sahiptir. Krediler ve alacaklar konusunda da durum farklı değildir. Mevduat bankaların buradaki payı $\% 89,59$ iken, katılım bankalarının ki \%5,15, diğer banka türünün ise \%5,26 seviyesindedir. Toplanan fonlara bakıldığında, toplanan mevduatın tümü geleneksel bankalar ve katılım bankaları sistemindedir; yatırım ve kalkınma bankalarının payının sıfır olmasının nedeni bu bankacılık türünün mevduat toplama yetkisinin olmamasıdır. Son olarak mevduat dışı kaynaklar kısmında mevduat bankaları \%83,27, katılım bankaları \%3,95, diğer banka türü ise \%12,78'lik bir paya sahiptir. Grafikten de görüleceği üzere sektördeki hâkim güç mevduat bankalarıdır. Dolayısıyla bankacılık sektörü ile mevduat bankalarının oranları birbiriyle büyük oranda aynı yönde olacaktır.

\subsection{Sermaye Yeterliliği Oranı}

Sermaye yeterliliği, bankanın finansal sağlamlığının en temel göstergelerinden biridir. Sermaye yeterliliği bankanın sahip olduğu özkaynakların kredi, piyasa ve operasyonel bileşenlerden oluşan risk ağırlıklı varlıklar karşısındaki yeterlilik derecesi konusunda genel bir fikir vermektedir. Sermaye Yeterliliği Oranı şöyle hesaplanır:

$$
\text { Sermaye Yeterliliği Oranı }=\frac{\text { Özkaynaklar }}{\text { Risk Ağırlıklı Varlıklar }}
$$

$\mathrm{Bu}$ oran Basel kriterleri kapsamında en az \% 8 olmalıdır. Ancak ülkemizde, BDDK, bankaların finansal sağlamlığını daha üst seviyede tutmak amacıyla bu oranın 12'nin üstünde olmasını istemektedir. Bu oran ve bileşenlerinin Türk bankacılık sektöründeki yıllar itibarıyla oransal gelişimi Grafik 2'de sunulmuştur.

\section{Grafik 2: Sermaye Yeterliliği Oranı ve Bileşenlerinin Sektörel Gelişimi}

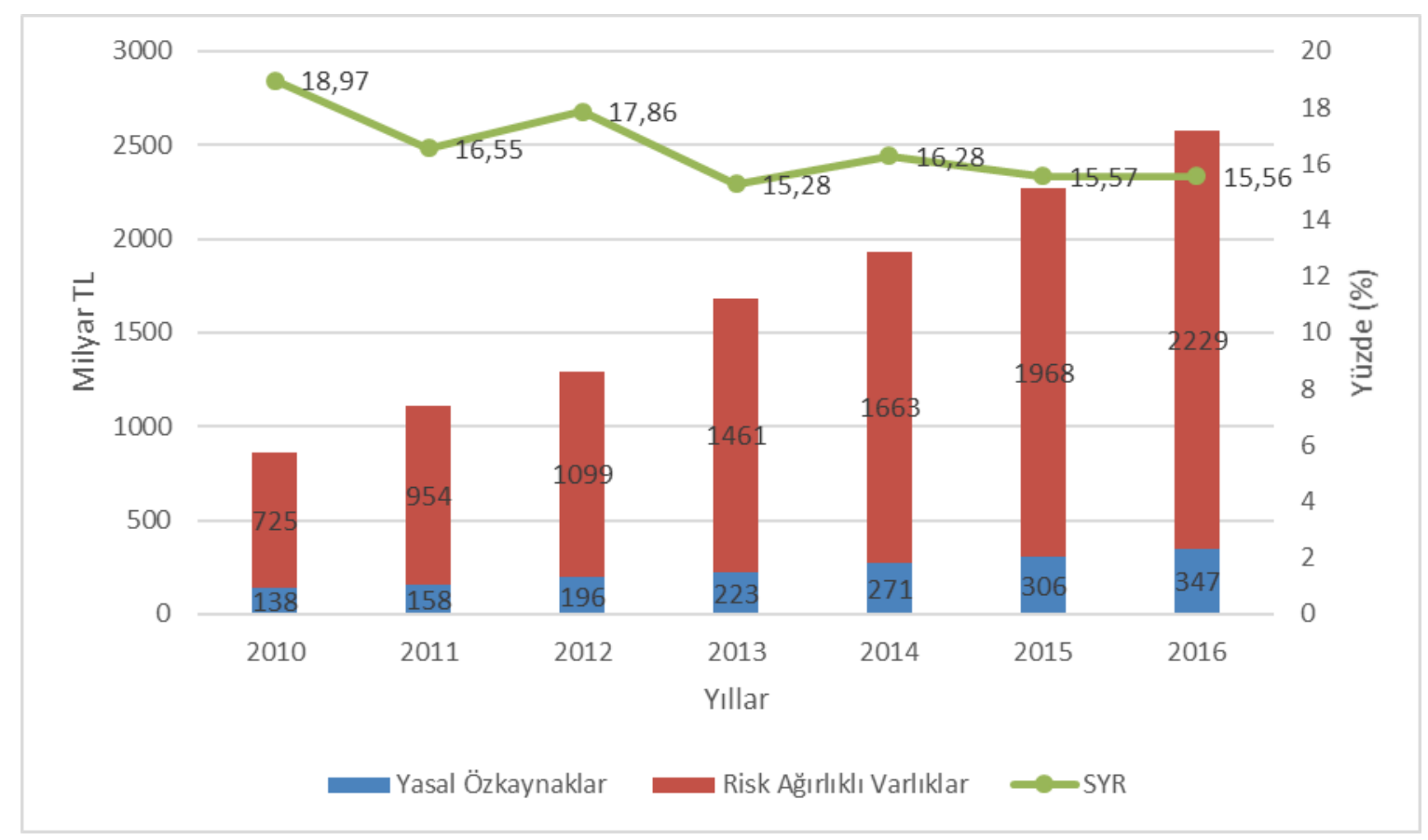

Kaynak: BDDK, Türk Bankacılık Sektörü Temel Göstergeleri, Aralık 2016, s. 20. 
Sermaye yeterlilik oranının yıllar itibarıyla değişimine bakıldığında, Grafik 2'de görüleceği üzere, yasal üst sınır olan 12'nin üstünde olmakla beraber 2010'dan bu yana genel olarak düşme eğilimindedir. Bunun sebebi risk ağırlıklı varlıkların 2010 yılından 2016'ya kadar yaklaşık 3 kat artmışken, özkaynaklar 2,5 katı dolaylarında artmıştır. Risk ağırlıklı varlıkların bileşenlerine bakıldığında ise buradaki artışın temel kaynağının kredi ve alacaklardaki artıştan dolayı olduğu açıktır. Bu çerçevede Grafik 3'te kredi ve alacaklardaki değişim, geleneksel bankalar, katılım bankaları, yatırım ve kalkınma bankaları ile sektör toplamı açısından ele alınmıştır.

\section{Grafik 3: Banka Grupları Bazında Kredi ve Alacakların Dağılımı 2010 - 2015}

\begin{tabular}{|c|c|c|c|c|c|c|c|c|}
\hline \multirow{10}{*}{ 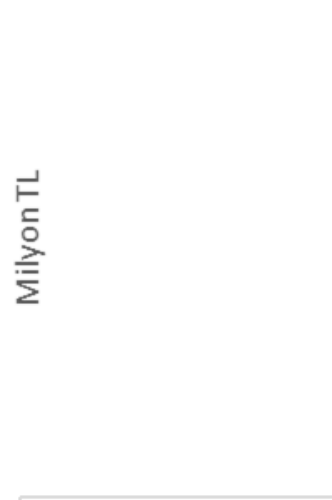 } & \multicolumn{7}{|l|}{1800000} & 1800000 \\
\hline & \multirow{2}{*}{\multicolumn{7}{|c|}{1600000}} & 1600000 \\
\hline & \multirow{2}{*}{\multicolumn{7}{|c|}{1400000}} & 1400000 \\
\hline & \multirow{2}{*}{\multicolumn{5}{|c|}{1200000}} & & & 1200000 \\
\hline & \multicolumn{4}{|l|}{1000000} & & & & \\
\hline & \multicolumn{8}{|l|}{800000} \\
\hline & \multicolumn{8}{|l|}{600000} \\
\hline & \multicolumn{8}{|l|}{400000} \\
\hline & \multicolumn{8}{|l|}{200000} \\
\hline & 0 & 2010 & 2011 & 2012 & 2013 & 2014 & 2015 & \multirow[t]{5}{*}{0} \\
\hline \multicolumn{2}{|c|}{ Kalkınma ve Yatırım Bankaları } & 18946 & 27571 & 35421 & 52187 & 63483 & 80820 & \\
\hline \multicolumn{2}{|l|}{ Katılım Bankaları } & 31.389 & 39.477 & 49.150 & 64.736 & 68267 & 79.729 & \\
\hline \multicolumn{2}{|l|}{ Mevduat Bankaları } & 489916 & 636718 & 733518 & 963338 & 1146203 & 1377697 & \\
\hline \multicolumn{2}{|l|}{ Sektör } & 540251 & 703766 & 818089 & 1080261 & 1277953 & 1538246 & \\
\hline \multicolumn{8}{|c|}{ Yıllar } & \\
\hline
\end{tabular}

Kaynak: BDDK, TBB, TKBB, 2016.

Grafik 3 incelendiğinde genel olarak banka gruplarının tümünde ve dolayısıyla sektör toplamında kullandırılan kredi rakamlarında artış söz konusudur. Bu çerçevede 2010 yılında 540.251 milyon TL olan toplam kredi ve alacaklar, 2016 yılında yaklaşık 3 kat bir artışla 1.538.246 milyon TL olmuştur. Sektörün 2015 yılı kredi ve alacaklar toplamı 2010 yılındaki toplamın yaklaşık olarak 3 katına ulaşmıştır. Sermaye yeterliliği bağlamında bakıldığında kredi ve alacaklardaki artışın sermaye yeterliliği oranının düşmesindeki en temel etkenlerden biri olduğu açıkça ifade edilebilir.

Sermaye yeterlilik rasyosunun düşmesi özkaynaklardaki artışın yetersiz kalmasıyla da açıklanabilir. Bu bakımdan Grafik 4'te banka grupları ve tüm sektörün toplam aktiflerinin içindeki özkaynakların oranının yıllar itibarıyla değişimi verilmiştir. 
Grafik 4: Özkaynaklar/Toplam Aktifler

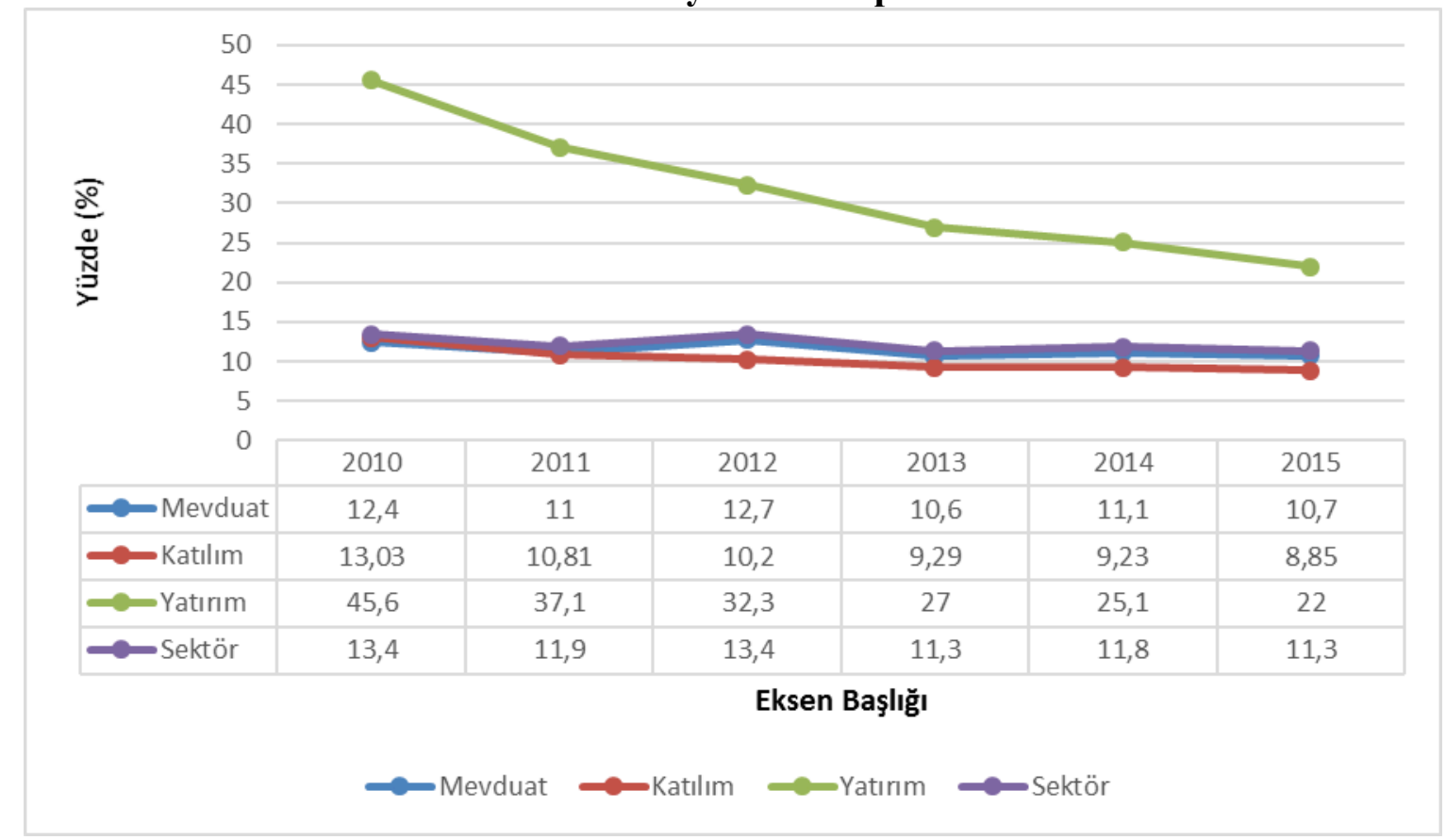

Kaynak: BDDK, TBB, TKBB, 2016.

Grafik 4 incelendiğinde özkaynakların yıllar itibarıyla gerek bankacılık sektörü içinde gerekse de banka grupları bazında toplam aktifler içindeki payının giderek düştüğü görülmektedir. Bu durum sermaye yeterliliği oranın hesaplanmasında oranın düşük çıkmasındaki etkenlerden biridir.

Sermaye yeterliliği oranındaki gelişimi banka grupları bazında gösteren Grafik 5 'te ise sermaye yeterliliği oranı mevduat bankaları, katılım bankaları, yatırım ve kalkınma bankaları ile sektör bazında ayrı ayrı olarak verilmiştir.

Grafik 5: Banka Grupları Bazında Sermaye Yeterliliği Oranının Gelişimi 2010 - 2016

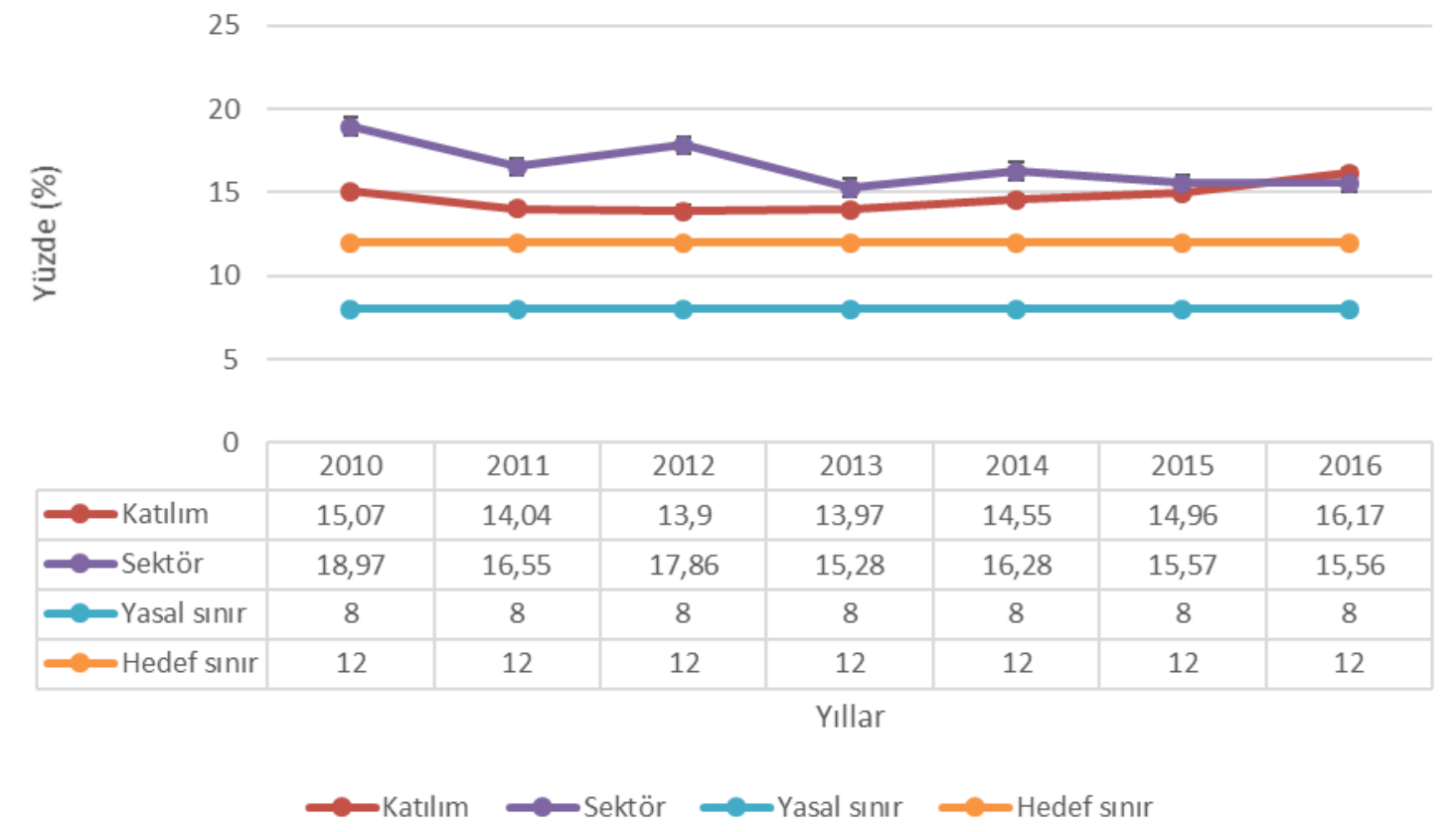

Kaynak: BDDK, TBB, TKBB, 2016. 
Grafik 5'te sermaye yeterliliği oranı banka grupları bazında ele alındığında her üç grupta da düşme eğiliminin olduğu gözlenmektedir. Her ne kadar yasal sınırın üzerinde izlese de sektörün sermaye yeterliliği oranı 2010 yılında \% 15,07 iken 2016' da bu oran \% 15,56'ya düşmüştür.

Öncelikle yatırım ve kalkınma bankalarına bakıldığında Söz konusu düşüşün nedeni yine kredi ve alacaklardaki artışla açıklanabilir. Nitekim 2010 yılında 27.571 milyon TL olan kredi ve alacaklar kalemi 2015 yılında 80.820 milyon TL'ye dolayisiyla yaklaşık olarak 3 katına ulaşmış buna karşılık özkaynaklar kalemi 15.445 milyon TL'den 23.470 milyon TL'ye diğer bir ifadeyle 1,5 katına ulaşmıştır.

Mevduat bankalarında sermaye yeterliliği oranının gelişimi sektördeki gelişimle aynı yönde olduğu görülecektir. Bunu sebebi mevduat bankalarının sektördeki $\% 90$ civarındaki payından ileri gelmektedir. Dolayısıyla sektör için yapılan açıklamalar mevduat bankaları için de hemen hemen aynen geçerlidir.

Katılım bankalarında ise yine yasal sınırın üstünde olmakla beraber sermaye yeterlilik oranı 2013 yılına kadar bir düşme eğilimi göstermiş, ancak sonraki yıllarda hemen hemen ilk baştaki seviyesine tekrar gelmiştir. Kredi ve alacaklar 2015 yılında 2010 yılına göre yaklaşık olarak 2,5 katına ulaşmasına rağmen sermaye yeterlilik oranının aynı doğrultuda bir seyir izlemesinde kredi riski oranının düşük olması etken olarak gösterilebilir. Kredi riskinin düşük olması katılım bankalarının doğasından kaynaklanan bir durumdur. Çünkü katılım bankalarında fon kullandırımlarında mutlaka bir varlık olmak zorundadır. Ancak diğer banka gruplarında böyle bir zorunluluk bulunmamaktadır. Nitekim geleneksel bankalarda herhangi bir varlığa dayalı olmaksızın kullandırılan fonların, toplam kredi ve alacaklar içindeki payı yaklaşık olarak \%26 dolaylarında iken katılım bankalarında bu oran sıfırdır.

\subsection{Faiz Gelirleri ve Kârlıık Göstergeleri}

Sermaye yeterliliği oranının gelişimi bankaların faaliyetleri sürecinde en çok kârlılıkları üzerinde etkili olmaktadır. Şöyle ki sermaye yeterliliği oranının düşmesi, risk ağırlıklı varlıklardaki artışın, özkaynaklardaki artışın önüne geçmesiyle mümkün olabilir. Sektörde ve özellikle kalkınma ve yatırım bankalarının sermaye yeterlilik oranının aşağı yönlü olması kredi hacmindeki genişlemeye, dolayısıyla faiz gelirlerindeki artışa işaret etmektedir. Bu bakımdan bu kısımda faiz gelirleri ve kârlılığa ilişkin verilere ve değerlendirmelere yer verilmiştir.

\subsubsection{Aktif ve Özkaynak Kârlılığı Oranı}

Aktif kârlılığı oranı bir kuruluşun sahip olduğu tüm varlıkları ne derece verimli kullandığını gösteren bir orandır. Özkaynak kârlılığı oranı da ortakların işletme üzerindeki haklarının ne derece verim sağladığını gösteren bir orandır. Bankacılık sektöründe genel olarak her iki oranın da yüksek çıkması tercih edilir. Bu oranların hesaplanması ise şöyledir:

$$
\text { Aktif Kârlılı̆̆ }=\frac{\text { Net Dönem Karı }}{\text { Toplam Aktifler }} \text { ve Özkaynak Kârlılı̆̆ı }=\frac{\text { Net Dönem Karı }}{\text { Özkaynaklar }}
$$

Bu formüller kullanılarak katılım bankalarının ve sektörün 2010 - 2016 yıllarına ilişkin kârlılık oranları hesaplanmış ve Grafik 6 oluşturulmuştur. 


\section{Grafik 6: Banka Grupları Bazında Net Dönem Kârı /Toplam Aktifler Oranı}

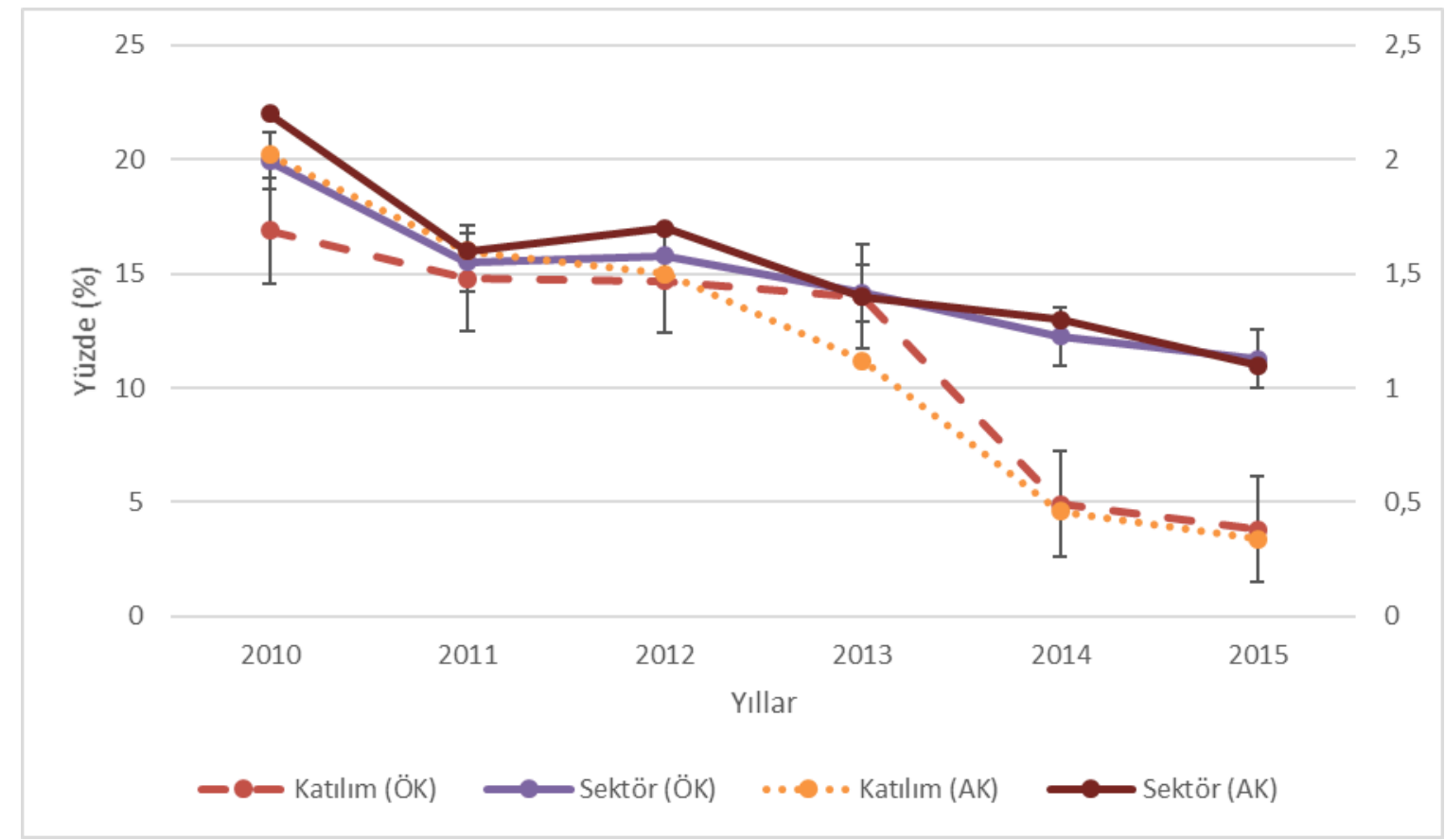

Kaynak: BDDK, TBB, TKBB, 2016.

Grafik 6, her iki kârlılık oranının yıllar itibarıyla düşme eğiliminde olduğunu göstermektedir. Bankacılık sektöründe sermaye yeterlilik oranının yıllar itibarıyla aşağı yönlü hareketi daha fazla kredi kullandırılması anlamına gelmektedir. Dolayısıyla bu durumda bankanın faiz gelirlerinde bir artış ortaya çıkması ve bankanın kârını arttırması beklenir. Ancak yukarıdaki grafik kârlılığın gerek sektörde gerek katılım bankalarında yıllar itibarıyla düştüğünü göstermektedir. Eğilimin bu yönde olması faiz dış1 giderlerdeki artışla açıklanabilir. Analizin daha sağlıklı olması için faiz (kâr payı) geliri ve giderleri kalemleri de incelenmiştir (Bkz. Grafik 7).

\subsubsection{Faiz (Kâr Payı) Gelirleri/Toplam Faaliyet Gelirleri (Giderleri)}

Katılım bankalarının ve bankacılık sektörünün sermaye yeterlilik oranının yıllar itibarıyla düşüş eğilimi olması durumunda bankacılık sektöründe faiz (kâr payı) geliri ve giderleri kalemlerinde artış ortaya çıkması beklenir. Nitekim Grafik 7'de katılım bankaları ve bankacılık sektöründe faiz (kâr payı) geliri ve giderleri ile net faiz (kâr payı) geliri kalemlerinin yıllar itibarıyla artış eğiliminde olduğu görülmektedir. 


\section{Grafik 7: Banka Grupları Bazında Yıllar İtibarıyla Faiz (Kar Payı) Geliri ve Giderinin Gelişimi (Milyon TL)}

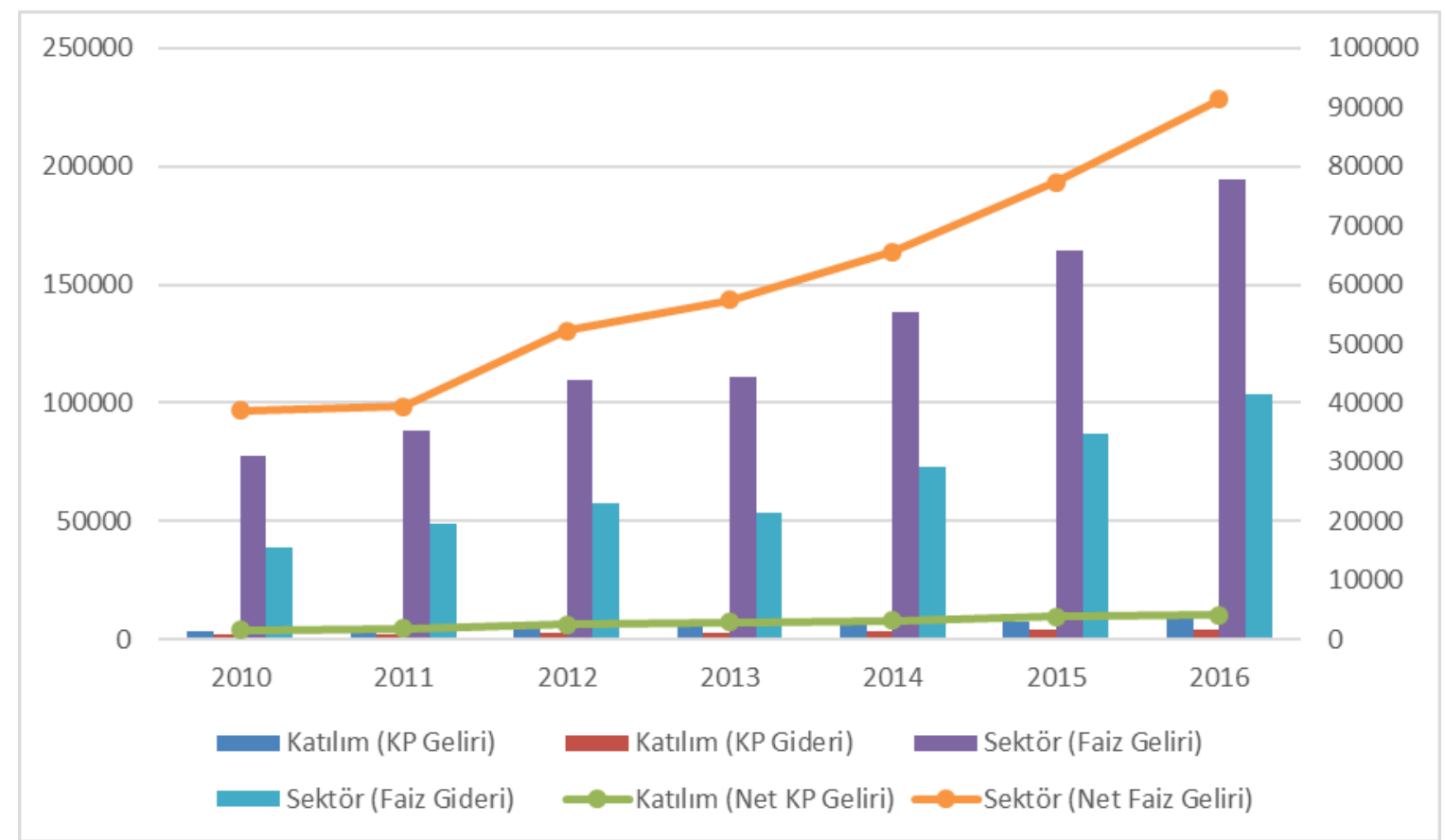

Kaynak: BDDK, TBB, TKBB, 2016.

Grafik 7'de görüleceği üzere katılım bankalarında ve bankacılık sektöründe faiz (kâr payı) geliri ve gideri kalemleri artış eğilimindedir. Sermaye yeterlilik rasyosu katılım bankalarında 2010 yılından 2016 yılına geçişte yaklaşık olarak \%15 düşmüş buna karşılık net faiz gelirlerinde yine yaklaşık olarak \%168,57'lik bir artış sağlanmış başka bir ifadeyle net faiz geliri 2,7 katına çıkmıştır. Bankacılık sektörünün geneli açısından ise sermaye yeterlilik oranı yaklaşık olarak $\% 18$ düşüş göstermişken, buna karşıl1k faiz gelirlerinde \%136,23 düzeyinde bir artış gerçekleşmiş başka bir ifadeyle artış 2,4 katına ulaşmıştır. Bu anlamda katılım bankalarının bankacılık sektörüne göre karlılık noktasında daha iyi bir performans ortaya koyduğu ileri sürülebilir.

\section{Sonuç}

Bölgesel ve küresel çapta yaşanan ve bazılarının etkilerini uzun yıllar sürdürdüğü finansal krizler nedeniyle ülkeler finans sektörünü, özellikle de bankacılık sektörünü sürekli güçlendirme arayışı içerisinde olmuşlardır. Bu amaçla oluşturulan BIS bünyesindeki Basel Komitesi tarafindan yayınlanan Basel kriterleri "Basel I kriterleri" ile başlamış geçmişteki ve günümüzdeki kriz tecrübeleri ile sürekli yenilenerek Basel III'e kadar gelmiştir. Bankacılık sektöründe uluslararası düzeyde sağlamlığını artırmayı hedefleyen Basel kriterlerinin biri de bankacılık sektörünün sermaye yeterliliğine yönelik kriterleri çerçevesindeki "sermaye yeterlilik oranı"dır. Yasal özkaynakların risk ağırlıklı varlıklara oranlanmasıyla elde edilen bu oran Komite tarafindan 8 olarak belirlenmiştir. Ancak ülkeler kendi içinde bu oranı daha yukarıda belirleme konusunda serbest bırakılmışlardır. Türkiye'de BDDK bankalardan bu oranı 12'nin altına düşürmemeleri talep etmektedir. $\mathrm{Bu}$ oranın ülkemizde daha yüksek bir oranla hedeflenmesi sektörün daha sağlam bir temel üzerinde yapılanma isteğini göstermektedir. Nitekim 2000 ve 2001 yıllarında yaşanan kriz Türkiye için iyi bir tecrübe olmuş ve bu süreçten sonra bankacılık sektöründe daha ihtiyatlı bir yaklaşım 
benimsenmiştir. Nitekim 2008 küresel finans krizinin Türk bankacılık sektörü üzerindeki etkisinin diğer ülkelere göre çok daha az olması alınan tedbirlerin etkili olduğunun en önemli göstergelerindendir.

Türk bankacılık sektöründe 2010 - 2016 verilerine dayanılarak sermaye yeterlilik oranında günümüze doğru bir düşme eğilimi olduğu gözlenmektedir. Bu düşme Grafik 2 'de değinildiği üzere genel olarak özkaynaklardaki artışın risk ağırlıklı varlıklardaki artışa göre daha düşük seyretmesi ile açıklanabilir. Nitekim Grafik 4'te de özkaynakların toplam aktifler içindeki payının yıllar itibarıyla düştüğü açıkça gözlemlenmektedir. Sermaye yeterlilik oranının düşmesinin özel nedenleri ise risk ağırlıklı varlıkların bileşenlerini oluşturan kredi riskine maruz varlıklar, piyasa riskine maruz varlıklar ve operasyonel riske maruz varlıklardaki artışla açıklanabilir. Bu bileşenlerden en dikkat çekici olan kredi riskine maruz varlıklar olarak gösterilebilir. Nitekim gerek katılım bankalarında gerekse de bankacılık sektörünün genelinde krediler (kullandırılan fonlar) yıllar itibarıyla sürekli artmıştır. Buna karşılık özkaynakların hem toplam olarak tutarı azalmış hem de aktifler içindeki payı giderek düşmüştür.

Kredilerdeki artışın, katılım bankalarının ve bankacılık sektörünün faiz (kâr payı) gelirleri üzerinde olumlu bir etki yaptığı ifade edilebilir. Nitekim Türk bankacılık sektöründe gerek katılım bankalarının gerekse de tüm bankacılık sektörünün faiz (kâr payı) gelirleri ve buna bağlı olarak yıllar itibarıyla net faiz (kâr payı) gelirleri sürekli bir artış sergilemiştir. Buna bağlı olarak gerek vergi öncesi gerekse de vergi sonrası kârlılık rakamları da artmıştır. Ancak aktif ve özkaynak kârlılığ yıllar itibarıyla düşme eğilimi göstermiştir. $\mathrm{Bu}$ durumun yaşanmasında faiz dışı gelir ve gider kalemlerindeki artış ve azalışların ve aktif büyüklüğünün artmasının etkili olduğu öne sürülebilir.

Analizlerde dikkat çeken bir diğer husus da katılım bankalarının sermaye yeterlilik oranında yaşanan azalmanın bankacılık sektörünün genelinde yaşanan düşmeye göre daha düşük olduğuna yöneliktir. Ancak buna karşılık katılım bankaları yıllar itibarıyla daha fazla net kâr payı geliri artışı sağlamıştır. Bu noktada sektörün önemli bir büyüklügünü yürüten konvansiyonel bankaların da bu noktada aynı kar payı artış oranını yakalaması sektör açısından büyük önem arz etmektedir.

Katılım bankaları ve bankacılık sektöründe yıllar itibarıyla sermaye yeterlilik oranın düşme eğilimi göstermesine rağmen, bugün gelinen noktada sermaye yeterlilik oranı BDDK'nın bankalara hedef olarak belirlediği oranının çok üzerindedir. Nitekim Türkiye dışındaki birçok ülkede bankacılık sektörünün kamu desteğine ihtiyaç duyduğu küresel kriz süreci ve sonrasında Türk bankacılık sektörü halen sağlam göstergeler eşliğinde yoluna devam etmektedir. Dolayısıyla bu kapsamda, sermaye yeterlilik oranı ve dolayısıyla farklı risk grupları çerçevesinde bankacılık sektörü için bir tehlikenin olmadığı rahatlıkla söylenebilir. Bu noktada sektör üzerinde BDDK'nin etkin gözetim ve denetimi devam ettirilmeli, güncel gelişmeler ve diğer ülkelerdeki iyi uygulamalar takip edilmelidir. 


\section{Kaynakça}

Atiker, M. (2005). 1Basel I ve Basel II, Konya Ticaret Odası Etüd-Araştırma Servisi, $41(8)$.

Bankacılık Düzenleme ve Denetleme Kurumu-BDDK (2010). Sorularla Basel III, BDDK Risk Yönetimi Dairesi, Aralık.

Bank For International Settlements-BIS (2010). Basel III: A Global Regulatory Framework for More Resilient Banks and Banking Systems, Basel, Switzerland.

Bank For International Settlements-BIS (2012). Basel III: International Regulatory Framework for Banks, http://www.bis.org/bcbs/basel3.htm, (05.03.2016).

Bankacılık Düzenleme ve Denetleme Kurumu-BDDK (2005). 10 Soruda Yeni Basel Sermaye Uzlaşısı (Basel II), BDDK Raporu, Ocak.

Bankacılık Düzenleme ve Denetleme Kurumu (2016). Türk Bankacılık Sektörü Temel Göstergeleri, Aralık.

Basel II ve KOBİ'ler Çalışma Grubu (2006). Basel II'nin KOBİ'lere Etkiler, Bankacılar Dergisi, 58: 3-62.

Boyner, Ü. (2011). Uluslararası Bankacılık ve Finans Sisteminin Yeni Mimarisi ve Türk Bankalarına Etkileri Konferans1, 31 Mayıs 2011, İstanbul.

Elizalde, A. (2007). From Basel I to Basel II: An Analysis of the Three Pillars, CEMFI Working Paper, 0704, June, Madrid, Spain.

Goodhart, Charles (2011). The Basel Committee on Banking Supervision A History of the Early Years, 1974-1997, Cambridge University Press, New York.

Horasan, M. ve Horasan, İ. (2012). Kredilendirme Süreci ve Basel II Kriterleri ile Karşılaştırılması”, Marmara Üniversitesi İIBF Dergisi, 32 (1), 201-230.

Karabıyık, L. ve Anbar, A. (2006). Basel II’nin Gelişmekte Olan Ülkelere Olası Etkileri, MUFAD Dergisi, 32.

Koğar, Çiğdem (2010). Küresel Finansal Sistemin Reformuna Yönelik Çalışmalar, 4 Ekim, Türkiye Bankalar Birliği'nde Yapılan Sunum, İstanbul.

Mermeod, A.Y. ve Ceran, Mustafa (2011). "Basel III Doğrultusunda Bankacılık Riskleri ve Sermaye Yeterliliği; Türk Bankacılık Sektörü Üzerine Karşılaştırmalı Bir Analiz", Finansal Araştırmalar ve Çalışmalar Dergisi, 2 (4).

Penikas, Henry (2015). History of Banking Regulation As Developed by the Basel Committee on Banking Supervision In 1974 - 2014 (Brief Overview), Banco De Espana, Estabilidad Financiera, No: 28., May.

Şahin, İ. (2013). Küresel Finansal Kriz Esnasında Geliştirilen Bankacılık Düzenlemelerinden Basel III Kriterlerinin Kapsamı ve Uygulama Süreci, Muhasebe ve Finansman Dergisi, Temmuz.

Yardımcıoğlu, M. ve Çam, A. Veli (2007). Sermaye Piyasalarındaki Derecelendirme Müessesesinin Basel II Kapsamında Değerlendirilmesi, Mali Çözüm Dergisi, Mart-Nisan: 59-70. 


\title{
Investigation of the Effects of Basel Capital Adequacy Ratio Change on the Turkish Banking Sector: Comparative Conventional and Islamic Banking with Ratio Analysis
}

\author{
Özgür ÇATIKKAŞ \\ Marmara University \\ School of Banking and Insurance \\ İstanbul, Turkey \\ orcid.org/0000-0002-7774-5882 \\ ozgurcatikkas@marmara.edu.tr
}

\author{
Ayhan YATBAZ \\ Manisa Celal Bayar University \\ School of Applied Sciences \\ Manisa, Turkey \\ orcid.org/0000-0002-6059-4176 \\ ayhanyatbaz@hotmail.com
}

\author{
Selim DURAMAZ \\ Manisa Celal Bayar University \\ School of Applied Sciences \\ Manisa, Turkey \\ orcid.org/0000-0002-1257-0620 \\ selimduramaz@hotmail.com
}

\section{Extensive Summary}

The banking sector is the most important factor in the economic development of an country. Past experience has shown that the smallest problem in the banking sector can affect the whole economy negatively. In this respect, the banking sector needs to be well regulated and monitored. At this point, possible problems in the system can be prevented and the system will continue to work properly.

The banking sector has great prospects at the global level as well as in the country. Since the 1980s, tight control in customs has begun to emerge and trade and finance transactions between countries have reached the highest level as daylight has come. The 2007-2008 Global Financial Crisis also showed that the financial crisis in a country is not limited to that country alone. Because today a bank in one country can easily withdraw from a bank in another country. Likewise, individual and institutional investors can assess their money on investment instruments in another country. Therefore, the crisis in the banking and finance sector in one country can affect investors and financial institutions in another country. In this respect, regulating and monitoring the banking sector at international level is very important for the healthy operation of the system.

The Bank for International Settlements (BIS) is an internationally autonomous body established to ensure that the banking sector is internationally coordinated and to achieve a standard structure. At the end of 1974, "Basel Committee on Banking Supervision - BCBS" started its activities under the BIS. BIS, along with BCBS, has published a series of rules to improve financial stability in the banking sector in general and internationally in particular. These rules, known as Basel Criteria are applied today by Turkey and many other countries.

Basel I consensus was published in 1988 by the Basel Banking Supervision Committee in 1988 in order to make the balance sheet structure of the banks one of the most effective and most important representatives of the capital market to be stronger in 
the face of the global economic crises of 1970 and 1974 and the reflections of these crises in many countries in the banking sector. Thus, the first step of the Basel criteria has been taken into the world banking system. The Basel I criteria focuses on the amount of capital required to be recorded at a minimum to minimize the costs that may be incurred by municipalities in the event of the bankruptcy of any bank. Accordingly, in Basel I, the standards related to the capital adequacy that banks should have have been determined and a comprehensive definition of the capital of the bank has been made. Accordingly, the bank's capital is at least $8 \%$ of the risk-weighted assets. In the process, in 1996, with an arrangement added to Basel I, the banks have taken the place among the standards to allocate capital for the market risk they undertake in addition to credit risk, and they are formulated as follows.

In June 1999, the Basel Committee published three consultative texts on "Basel IINew Basel Capital Adequacy Consensus", taking into account developments in the financial markets, Basel I's lack of capital adequacy metrics and other shortcomings. The texts have been revised in the context of comments and suggestions received from the country supervisors and banks and other interested parties, and the final text under Basel II was published in June 2004.

Basel II, which is expected to move on three structural blocks: minimum capital adequacy, supervision of capital adequacy and market discipline, Basel II aims to improve effective risk management and market discipline in the banking system in general, to increase the effectiveness of capital adequacy measurements, to establish a sound and effective banking system, focused on the purpose of contributing to stability. At the same time, the Basel II consensus includes provisions on how to calculate the capital liability, how to manage the risks in the different structures, how to assess capital adequacy and how to explain the results to the public.

The transformation of large US investment banks into bank holding companies, the publicization of Fannie Mae and Fredi Mac organizations, the collapse of AIG bankruptcy, the division of Fortis Bank and then to sell, Iceland'da the largest commercial bank, then the banking system of the country to collapse completely, many countries, such as the country to provide a serious support packages in the country, such as the development of the current crisis, and the current system revealed some serious shortcomings.

The crisis that emerged in the banking sector, which is the main actor of the crisis, has spread all over the world in a short period of time by including the whole global financial sector and the country's economy in the process. On this living process, the Basel Committee on Banking Supervision presented a new capital regulation package to the public at its meeting on September 12,2010. Because it is the third reform package presented to the public by the committee after Basel I and Basel II, this study has received the Basel III Consensus worldwide.

Basel III envisages a comprehensive set of reform measures developed by the Basel Committee on Banking Supervision to strengthen regulatory, supervisory and risk management of the banking sector. These measures primarily target:

Basel III foresees some adjustments in banks' own funds, capital ratios and leverage and liquidity ratios. However, Basel III aims to achieve both the above objectives and the main objective is to increase both the capital quality of US and European banks and to have sufficient capital for crisis periods. At this point the capital 
is redefined and the amount of liquidity risk is determined and the minimum capital ratios that the bank should hold for all capital components are determined separately. Accordingly, it has been stated that the capital components of the banks should be at least $4.5 \%$ of the capital ratios and $6 \%$ of the main capital ratios. Total capital ratio continued at $8 \%$, no change was made to Basel II. With these ratios, it is necessary to allocate additional capital of $2.5 \%$ against a possible crisis of banks. Thus, the total capital adequacy ratio with capital reserve is 10.5 .

Although it is not compulsory to apply in countries outside the EU countries, the Turkish banking sector has made a considerable progress with the different regulations published by the BRSA. Even Basel II regulations have been enacted and have been published in the Official Gazette dated 28/06/2012 and numbered 28337 and entered into force on $01 / 07 / 2012$.

While the banks were being analyzed in the study, the banking system was divided into three categories based on the group. These; deposit banks, participation banks and investment and development banks. In order to better understand the position of the banking groups within the whole banking sector, sector information is also included. In the study, it was used traditional banks' name to express "deposit banks" and "investment and development" banks.

As a result of the study, it is observed that the capital adequacy ratio tends to decrease day by day in the Turkish banking sector based on 2010-2016 data. This can be explained by the fact that the increase in equity in general is lower than the increase in risk weighted assets. As a matter of fact, it is clearly observed that the share of own funds within total assets declined by years. Specific reasons for the decline in the capital adequacy ratio can be explained by the increase in assets exposed to credit risk, assets exposed to market risk and operational risk, which constitute the components of risk weighted assets. The most striking of these components is the exposure to credit risk assets. As a matter of fact, the credits (funds used) have continuously increased over the years, both in the participation banks and in the banking sector in general. On the other hand, the share of own funds both decreased in total and its share in assets decreased gradually.

In the analysis, it is another thing to note that the decline in the capital adequacy ratio of participation banks is lower than that of the overall banking sector. However, the participating banks have increased their net profit share increase over the years. In this point, it is very important for the sector to catch the same profit share increase rate at the same point in the conventional banks that carry out an important size of the sector.

Although capital adequacy ratios have not shown a tendency to decline in the participation banks and banking sector for years, the capital adequacy ratio at today's point is well above the ratio determined by the BRSA as a bank target. Indeed, the Turkish banking sector in many countries outside the banking sector in Turkey and after the global crisis that needs public support is still continuing on the path accompanied by robust indicators. Therefore, in this context, it can be said that there is no danger for the banking sector within the capital adequacy ratio and therefore different risk groups. 